\title{
Increased expression of NAD(P)H oxidase subunits, NOX4 and p22phox, in the kidney of streptozotocin-induced diabetic rats and its reversibity by interventive insulin treatment
}

\author{
T. Etoh ${ }^{1}$, T. Inoguchi ${ }^{1}$, M. Kakimoto ${ }^{1}$, N. Sonoda ${ }^{1}$, K. Kobayashi ${ }^{1}$, J. Kuroda ${ }^{2}$, H. Sumimoto ${ }^{2}$, H. Nawata ${ }^{1}$ \\ ${ }^{1}$ Department of Medicine and Bioregulatory Science, Graduate School of Medical Sciences, Kyushu University, \\ Fukuoka, Japan \\ ${ }^{2}$ Department of Molecular and Structural Biology, Graduate School of Medical Sciences, Kyushu University, \\ Fukuoka, Japan
}

\begin{abstract}
Aim/hypothesis. An increased production of reactive oxygen species (ROS) could contribute to the development of diabetic nephropathy. $\mathrm{NAD}(\mathrm{P}) \mathrm{H}$ oxidase might be an important source of ROS production in kidney as reported in blood vessels. In this study, we show the increased expression of essential subunits of $\mathrm{NAD}(\mathrm{P}) \mathrm{H}$ oxidase, NOX4 and p22phox, in the kidney of diabetic rats.

Methods. The levels of mRNA of both NOX4 and p22phox were evaluated in kidney from streptozotocin-induced diabetic rats and age-matched control rats at 4 and 8 weeks after onset of diabetes by Northern blot analysis. The localization and expression levels of these components and 8-hydroxy-deoxyguanosine (8$\mathrm{OHdG}$ ), which is a marker of ROS-induced DNA damage, were also evaluated by immunostaining.

Results. The levels of both NOX4 and p22phox mRNA were increased in the kidney of diabetic rats as com-
\end{abstract}

pared with control rats. Immunostaining analysis showed that the expression levels of NOX4 and p22phox were clearly increased in both distal tubular cells and glomeruli from diabetic rats. Both the localization and the expression levels of these components were in parallel with those of 8-OHdG. Interventive insulin treatment for 2 weeks completely restored the increased levels of these components in the diabetic kidney to control levels in parallel with those of $8-\mathrm{OHdG}$. Conclusions/interpretation. This study provides evidence that $\mathrm{NAD}(\mathrm{P}) \mathrm{H}$ oxidase subunits, NOX4 and p22phox, were increased in the kidney of diabetic rats. Thus, NAD(P)H-dependent overproduction of ROS could cause renal tissue damage in diabetes. This might contribute to the development of diabetic nephropathy. [Diabetologia (2003) 46:1428-1437]

Keywords Oxidative stress, $\mathrm{NAD}(\mathrm{P}) \mathrm{H}$ oxidase, NOX4, p22phox, 8-hydroxy-deoxyguanosine, nephropathy.
An increased production of reactive oxygen species (ROS) is supposed to contribute to the development of diabetic vascular complications including nephropathy

Received: 21 November 2002 / Revised: 22 April 2003

Published online: 12 September 2003

C Springer-Verlag 2003

Corresponding author: T. Inoguchi MD, Department of Medicine and Bioregulatory Science, Graduate School of Medical Sciences, Kyushu University, Fukuoka 812-8582, Japan

E-mail: toyoshi@intmed3.med.kyushu-u.ac.jp

Abbreviations: ROS, reactive oxygen species; NAD(P)H oxidase, nicotinamide adenine dinucleotide phosphate oxidase; $8-\mathrm{OHdG}$, 8-hydroxy-deoxyguanosine; STZ, streptozotocin; mtDNA, mitochondrial DNA; PKC, protein kinase C.
$[1,2,3,4,5,6]$. However, the source of ROS production remains controversial. It has been postulated that hyperglycaemia could produce ROS through various mechanisms such as enhanced formation of advanced glycation endproducts (AGEs) [3], altered polyol pathway activity $[2,7]$ and increased superoxide release from mitochondria [8]. In contrast, accumulating evidence has suggested that $\mathrm{NAD}(\mathrm{P}) \mathrm{H}$ oxidase is the most important source of ROS production in vascular tissues and cells $[9,10,11,12]$. Recent reports have implicated that this enzyme might be involved in the pathophysiology of vascular diseases including hypercholesterolaemia [13], atherosclerosis [14, 15, 16], and hypertension [17]. Previously, we showed that high glucose level stimulated ROS production through 
protein kinase $\mathrm{C}$ (PKC)-dependent activation of NAD(P)H oxidase in cultured aortic endothelial cells and smooth muscle cells [18]. This finding suggests that activation of $\mathrm{NAD}(\mathrm{P}) \mathrm{H}$ oxidase could account for an increased production of ROS in diabetes. In consistency with this idea, several reports have recently shown that the activity of $\mathrm{NAD}(\mathrm{P}) \mathrm{H}$ and the levels of its subunit proteins are increased in the aortae from animal models of diabetes $[19,20]$ and in the saphenous vein and internal mammary artery from diabetic patients with coronary artery disease [21].

Since the kidney is also known to be an organ susceptible to oxidative damage [22,23], oxidative stress might play a role in the development of diabetic nephropathy as in other diabetic vascular complications. Although vascular oxidases are similar to the phagocytic NAD $(\mathrm{P}) \mathrm{H}$ oxidase, they have a unique family of enzymes [24]. The phagocytic $\mathrm{NAD}(\mathrm{P}) \mathrm{H}$ oxidase complex comprises a membrane-associated cytchrome b558 composed of gp91phox (NOX2) and p22phox and several cytosolic regulatory subunits (P47phox, p40phox, p67phox and Rac1 or Rac2). The hemebinding subunit of cytochrome b558 that is essential for enzyme activity is a gp91phox, a glycosylated flavoprotein associated with p22phox. As a homolog of gp91phox in the kidney, NOX4 (Renox) has been cloned recently $[25,26]$. It has been implicated that NOX4, as a major source of ROS production in the kidney, could have a role under pathological conditions $[25,26]$. We therefore speculated that NOX4 might be involved in development of diabetic nephropathy. The aim of this study is to evaluate the expression of NOX4 and p22phox in kidney from streptozotocin-induced diabetic rats and to relate these changes to oxidative damage to renal tissues.

\section{Methods and materials}

Animals. Male Wistar rats were bred under pathogen-free conditions at Kyushu University Animal Centre, Fukuoka, Japan. We formed two experimental groups: streptozotocin (STZ)-induced diabetic rats and age-matched control rats. The animals had free access to tap water and standard chow (Clea Japan, Tokyo). At 8 weeks of age, the rats were injected intraperitoneally with STZ (Sigma, St. Louis, Mo., USA) at $80 \mathrm{mg} / \mathrm{kg}$ body weight. One day after injection, diabetes was confirmed by the development of hyperglycaemia (>300 mg/dl blood glucose). For interventive insulin treatment, one-half of the diabetic rats were treated with insulin starting at 6 weeks after onset of diabetes. During the next 2 weeks, intermediate-acting insulin (Novolin N; Novo Nordisk, Tokyo, Japan) was subcutaneously administered twice a day. The doses of insulin to be given were determined each time from a sliding scale, according to blood glucose concentrations, to achieve strict glucose control. The study was approved by the committee for Ethics on Animal Experiments, Graduate School of Medical Sciences, Kyushu University and the Guide for Care and Use of Laboratory Animals.

Northern blot analysis. At 4 and 8 weeks after onset of diabetes, rats were anaesthetized by intraperitoneal injection of pen- tobarbital $(80 \mathrm{mg} / \mathrm{kg})$ and killed by bleeding before performance of surgical procedures. The kidney was rapidly excised and separated into cortices and medullae. Then, the samples were frozen in liquid nitrogen and kept at $-80^{\circ} \mathrm{C}$ until use. Total RNA was extracted using Isogen (Waco, Osaka, Japan) from the frozen samples. Of the total RNA, $20 \mu \mathrm{g}$ was electrophoresed on a $1 \%$ agarose gel containing $2.2 \mathrm{~mol}$ formaldehyde, and then transferred to a Hybond- $\mathrm{N}^{+}$nylon membrane (Amersham Pharmacia Biotech, Little Chalfont, UK). After immobilization by UV cross-linking, prehybridization was at $68^{\circ} \mathrm{C}$ for at least $2 \mathrm{~h}$ following the addition of ExpressHyb Hybridization Solution (Clontech, Palo Alto, Calif., USA). The membrane was hybridized with each probe, which was labelled using the Megaprime DNA Labelling System (Amersham Pharmacia Biotech) and $(\alpha-32 \mathrm{P})$ dCTP. cDNA probes for rat NOX4 encodes the region that corresponds to amino acids 1-360, and for rat $\mathrm{p} 22 \mathrm{phox}$ encodes full length. Unincorporated ${ }^{32} \mathrm{P}$ was removed using Biospin P30 columns (BioRad, Hercules, Calif., USA). The radioactivity corresponding to each band was visualized by a bioimage analyzer, Multi Bio Imager STORM (Amersham Pharmacia Biotech). The densities of individual bands were normalized to $18 \mathrm{~S}$ ribosomal RNA.

Immunostaining analysis. Immunostaining of NOX4 was carried out as described previously [26]. The kidneys were fixed in $10 \%$ formaldehyde, and embedded in paraffin. Paraffin sections were cut at $3 \mu \mathrm{m}$, and deparaffinized. After inactivation of endogenous peroxidase with $3 \% \quad \mathrm{H}_{2} \mathrm{O}_{2}$ in methanol for $15 \mathrm{~min}$ at room temperature, the sections were pre-incubated for $30 \mathrm{~min}$ with $1 \%$ bovine serum albumin in phosphate buffered saline (PBS). The samples were subsequently incubated with anti-human NOX4 rabbit polyclonal antibody [26] ( $1: 1000$ dilution) overnight at $4^{\circ} \mathrm{C}$, washed in PBS, and probed with anti-rabbit IgG antibody labelled with peroxidase [Histofine Simple Stain MAX PO(R), Nichirei Corp., Tokyo, Japan] for $30 \mathrm{~min}$ at room temperature. As a negative control, the primary antibody was replaced with sera obtained from a rabbit before immunization. The sites of peroxidase were visualized with diaminobenzidine (Nichirei Corp.). For p22phox staining, the samples were incubated with anti-human p22phox goat polyclonal antibody $(0.2 \mu \mathrm{g} / \mathrm{ml}$ ) (Santa Cruz Biotechnology, Santa Cruz, Calif., USA) overnight at $4^{\circ} \mathrm{C}$, washed in PBS, and probed with anti-goat IgG antibody labelled with peroxidase [Histofine Simple Stain MAX PO(G)] for $30 \mathrm{~min}$ at room temperature. As a negative control, the primary antibody was replaced with normal goat serum. The sections were counterstained with haematoxylin before being examined under a light microscope (Olympus, Tokyo, Japan).

For 8-hydroxy-deoxyguanosine $(8-\mathrm{OHdG})$ staining, the samples were incubated with anti-8-OHdG mouse monoclonal antibody $(1 \mu \mathrm{g} / \mathrm{ml})$ (Japan Institute for the Control of Aging, Fukuroi, Japan) overnight at $4^{\circ} \mathrm{C}$, washed in PBS, and probed with anti-mouse IgG antibody labelled with peroxidase [Histofine Simple Stain MAX PO(M)] for $30 \mathrm{~min}$ at room temperature, and the sites of peroxidase were visualized with diaminobenzidine. As a negative control, the primary antibody was replaced with mouse IgG.

Culture study. Human mesangial cells were obtained from Clonetics (East Rutherford, N.J., USA). The cells were maintained in a Mesangial Cell Growth Medium (MsGM) (Clonetics) containing $5 \%$ foetal calf serum in an atmosphere of $95 \%$ $\mathrm{O}_{2} / 5 \% \mathrm{CO}_{2}$ at $37^{\circ} \mathrm{C}$. The cells used in these experiments were from 4 th to 6 th passages. For the experiments, the cells were allowed to reach confluence in $100 \mathrm{~mm}$ dishes, and then the medium was changed to an MsGM supplemented with $0.5 \%$ serum and high glucose level $(400 \mathrm{mg} / \mathrm{dl})$ or normal glucose 

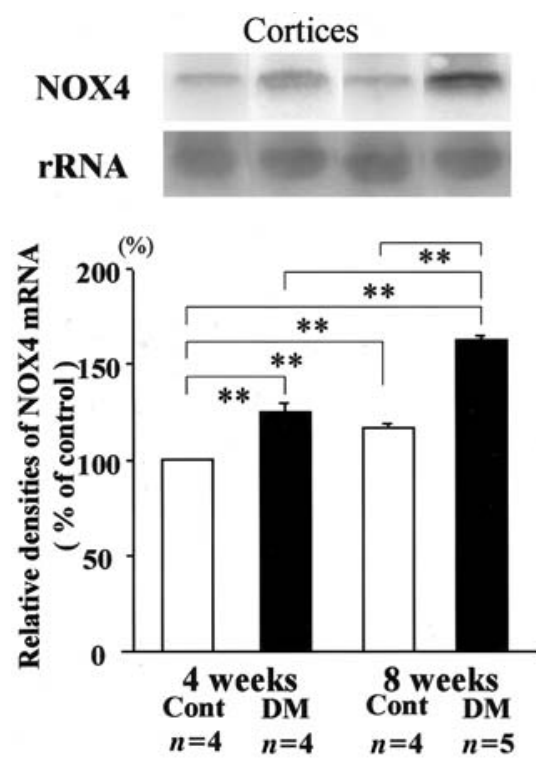

Fig. 1. NOX4 mRNA expression in kidney of control rats and streptozotocin-induced diabetic rats. Total RNA was isolated from renal cortices and medullae of control rats (Cont) and diabetic rats (DM) at 4 and 8 weeks after onset of diabetes. Levels of NOX4 mRNA expression were measured by Northern blot analysis. Levels of mRNA expression were normalized to $18 \mathrm{~S}$ rRNA and the results were expressed as mean percentages of control \pm SEM. $\mathrm{n}$, number of rats. $* p<0.05, * * p<0.01$

level $(100 \mathrm{mg} / \mathrm{dl})$. Firstly, the effect of high glucose level on ROS production in cultured mesangial cells was examined using electron spin resonance (ESR) spectroscopy as previously described [18]. Briefly, the cells were removed from the dishes by treatment with $0.25 \%$ trypsin, centrifuged at $800 \mathrm{~g}$ for 5 min, and suspended in the DMEM without serum at a concentration of $1 \times 10^{7}$ cells $/ \mathrm{ml}$. The nitroxide radical, carboxyTEMPO acetoxymethyl ester (CxT-AM), was added to the cell suspension at the final concentration of $20 \mathrm{mmol} / \mathrm{l}$ and the samples were mixed quickly but gently. Then, immediately, the samples were drawn into a gas-permeable Teflon tube (Zeus Industries, Raritan, N.J., USA) and inserted into a quartz ESR tube open at each end. Experiments were carried out at $37^{\circ} \mathrm{C}$. ESR spectra were recorded with an ESR spectrometer (JESRE-1X; JEOL, Akishima, Japan) operating at X-band (9.45 GHz). CxT-AM was hydrolyzed inside the cells, retained in the cytoplasm, and then reduced to the corresponding hydroxylamine, leading to the loss of paramagnetism. The ESR signal intensity decreased gradually after administration and the signal decay curve of CxT-AM was obtained by semi-logarithmically plotting the peak heights of the ESR signals. The curve was almost linear over the first 5 min of decay, allowing the initial velocity as the clearance constant (spin clearance rate). The spin clearance rate represents the rate of radical generation in intact cells. For Northern blot analysis, total RNA was extracted using Isogen (Wako, Osaka, Japan) from the cultured cells. cDNA probes for human NOX4 encodes in the region that corresponds to amino acids 324-491, and for human p22phox encodes full length.

Statistical analysis. All values shown are expressed as means \pm SEM. Statistical analysis was done by ANOVA followed by Fisher's comparison test. A $p$ value of 0.05 or less was considered statistically significant.

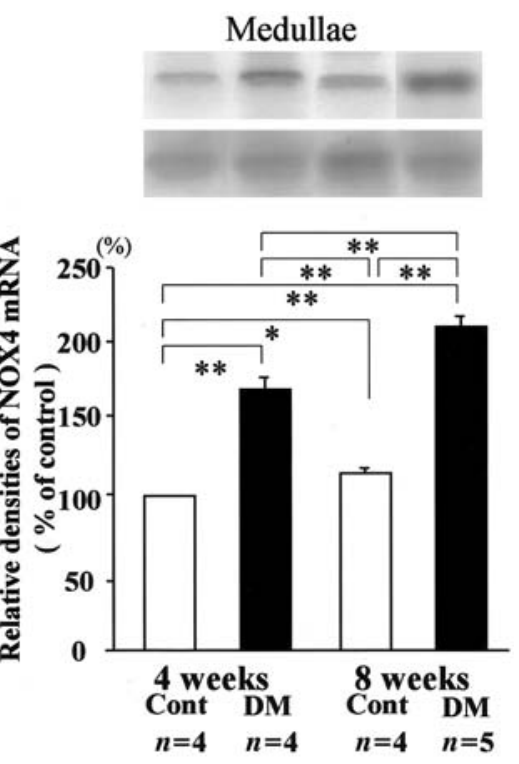

\section{Results}

mRNA Expression of NOX4 and p22phox in rat kidney. Northern blot analysis showed that rat NOX4 mRNA of about $4.4 \mathrm{~kb}$ was expressed with a faint $2.8 \mathrm{~kb}$ band in rat kidney. We found that the two blotting bands had a similar tendency, therefore, $4.4 \mathrm{~kb}$ size bands were used for analysis. The levels of NOX4 mRNA were increased in both renal cortices and medullae of diabetic rats as compared with those of the control rats at 4 and 8 weeks after onset of diabetes (Fig. 1). The levels of p22phox mRNA were also increased in both renal cortices and medullae of diabetic rats as compared with those of the control rats at 4 and 8 weeks after onset of diabetes (Fig. 2).

Immunostaining analysis of NOX4 and p22phox in rat kidney. To examine the localization and expression levels of NOX4 and p22phox protein in the rat kidney, we carried out immunostaining analysis 8 weeks after onset of diabetes. Strong positive stains of NOX4 were observed in distal tubular cells, whereas only faint stains could be detected in proximal tubular cells and glomeruli in the control rat kidney. In the diabetic rat kidney, the staining intensities of NOX4 were apparently stronger in both tubular cells and glomeruli than those in the control kidney (Fig. 3). The localization of p22phox stains was quite similar to that of NOX4 (Fig. 4). In the diabetic rat kidney, the staining intensities of p22phox were also apparently stronger in both tubular cells and glomeruli than those in the control rat kidney (Fig. 4). Similar results were obtained in all samples from diabetic rat and control rat kidneys.

Immunostaining analysis of $8-O H d G$. As a biomarker of ROS-induced DNA damage, 8-OHdG was evaluated in the rat kidney 8 weeks after onset of diabetes by immunostaining. In the diabetic rat kidney, the stain- 


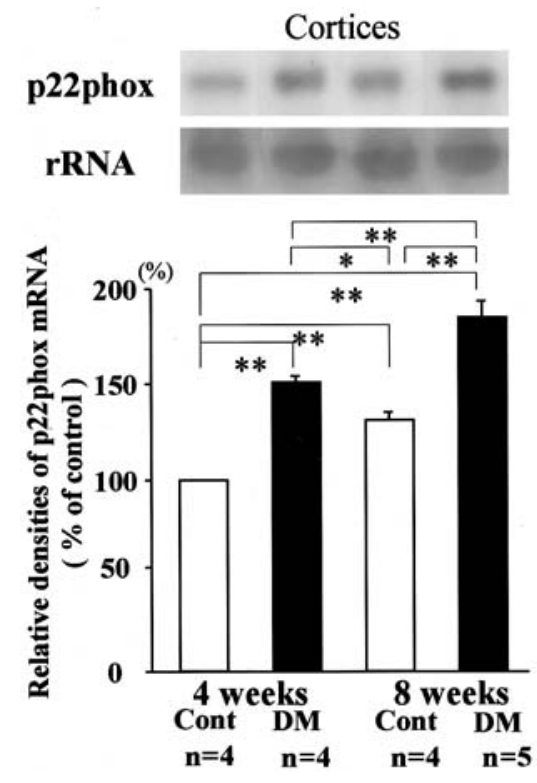

Fig. 2. p22phox mRNA expression in kidney of control rats and streptozotocin-induced diabetic rats. Total RNA was isolated from renal cortices and medullae of control rats (Cont) and diabetic rats $(\mathrm{DM})$ at 4 and 8 weeks after onset of diabetes. Levels

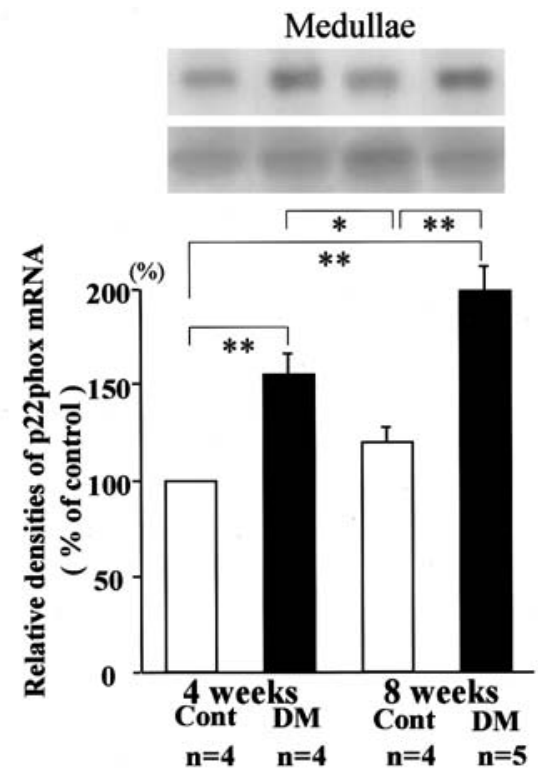

of p22phox mRNA expression were measured by Northern blot analysis. Levels of mRNA expression were normalized to $18 \mathrm{~S}$ rRNA and the results were expressed as mean percentages of control \pm SEM. $n$, number of rats. $* p<0.05, * * p<0.01$
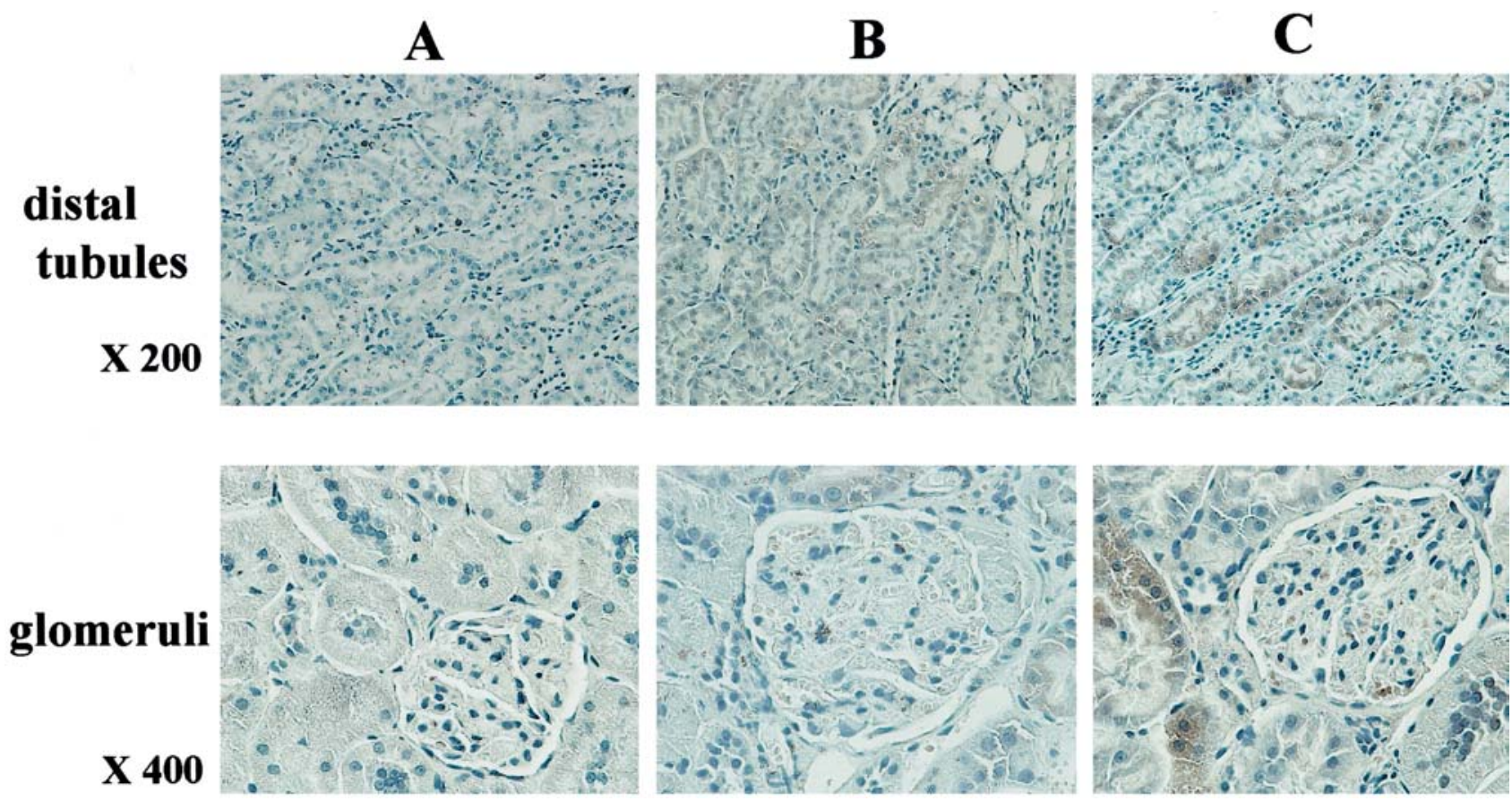

Fig. 3A-C. Immunostaining analysis of NOX4 expression in the kidney of control rats (B) and streptozotocin-induced diabetic rats $(\mathbf{C})$ at 8 weeks after onset of diabetes. The sections were incubated with anti-human NOX4 rabbit polyclonal antibody, probed with anti-rabbit IgG antibody labelled with peroxidase. As a negative control, the primary antibody was replaced with sera obtained from a rabbit before immunization (A). The sites of peroxidase were visualized with diaminobenzidine. The sections were counterstained with haematoxylin before being examined under a light microscope. The pictures are representative of the samples from four control rats and five diabetic rats. Similar results were obtained in all samples from control and diabetic rat kidneys ing intensities of $8-\mathrm{OHdG}$ were apparently stronger in tubular cells and to a lesser extent stronger in glomeruli than those in the control kidney (Fig. 5). The localization and staining intensities of $8-\mathrm{OHdG}$ were quite in parallel with those of NOX4 and p22phox expression. As for intracellular localization, positive 8OHdG stains were increased mainly in the cytosol and to a lesser extent increased in the nucleus in the diabetic rat kidney (Fig. 5). 


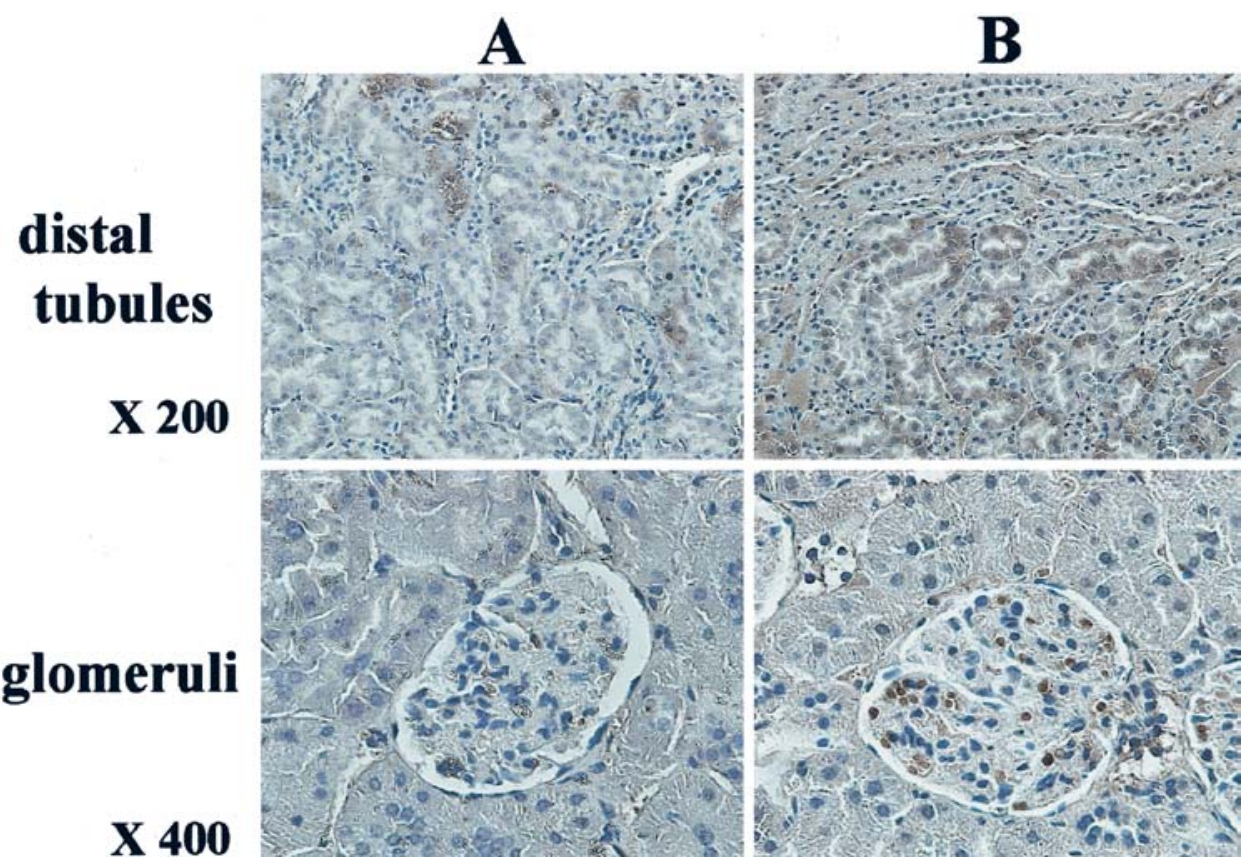

Fig. 4A, B. Immunostaining analysis of p22phox expression in kidney of control rats (A) and streptozotocin-induced diabetic rats $(\mathbf{B})$ at 8 weeks after onset of diabetes. The sections were incubated with anti-human p22phox goat polyclonal antibody, probed with anti-goat IgG antibody labelled with peroxidase. The sites of peroxidase were visualized with diaminobenzidi- ne. The sections were countersatined with haematoxylin before being examined under a light microscope. The pictures are representative of the samples from four control rats and five diabetic rats. Similar results were obtained in all samples from control and diabetic rat kidneys

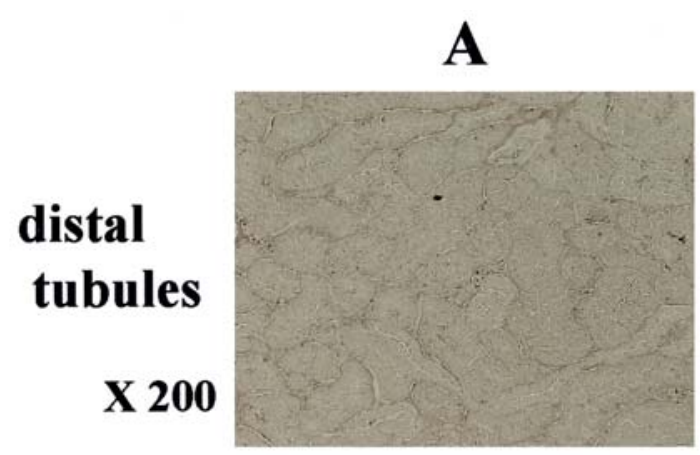

B
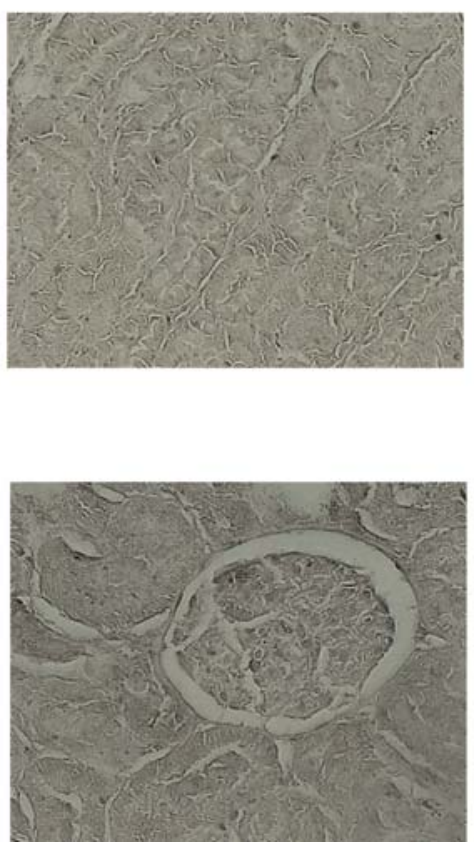

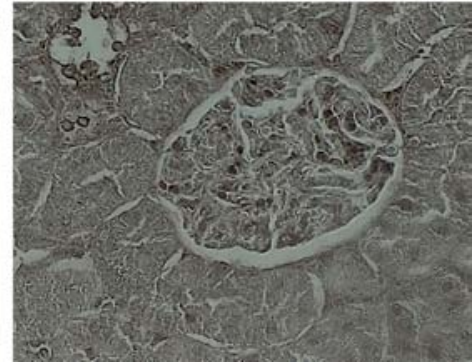

\section{glomeruli}

\section{$\mathbf{X} 400$}

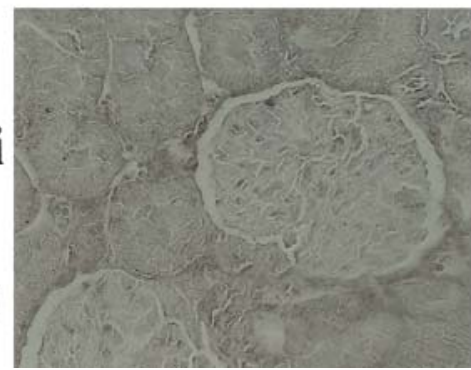

Fig. 5A-C. Immunostaining analysis of 8-OHdG in kidney of control rats $(\mathbf{B})$ and streptozotocin-induced diabetic rats $(\mathbf{C})$ at 8 weeks after onset of diabetes. The sections were incubated with anti-8-OHdG mouse monoclonal antibody, probed with anti-mouse IgG antibody labelled with peroxidase. As a nega- tive control, the primary antibody was replaced with mouse IgG (A). The sites of peroxidase were visualized with diaminobenzidine. The pictures are representative of the samples from four control rats and five diabetic rats. Similar results were obtained in all samples from control and diabetic rat kidneys 

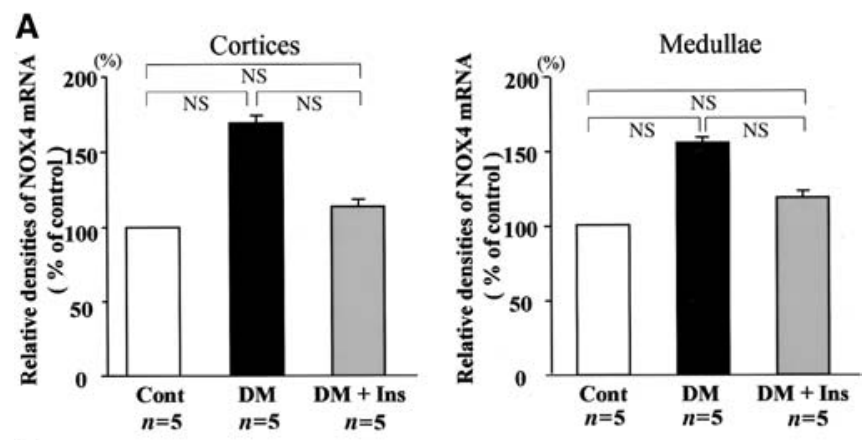

Interventive insulin treatment. STZ-induced diabetic rats were treated with insulin starting at 6 weeks after onset of diabetes. Glycaemic control was achieved during the next 2 weeks as follows: mean plasma glucose concentrations and fructosamine levels on the last day were $129 \pm 17 \mathrm{mg} / \mathrm{dl}$ and $193 \pm 3 \mathrm{mmol} / \mathrm{l}$ in control rats, $748 \pm 117 \mathrm{mg} / \mathrm{dl}$ and $310 \pm 11 \mathrm{mmol} / 1$ in non-treated diabetic rats, and $109 \pm 13 \mathrm{mg} / \mathrm{dl}$ and
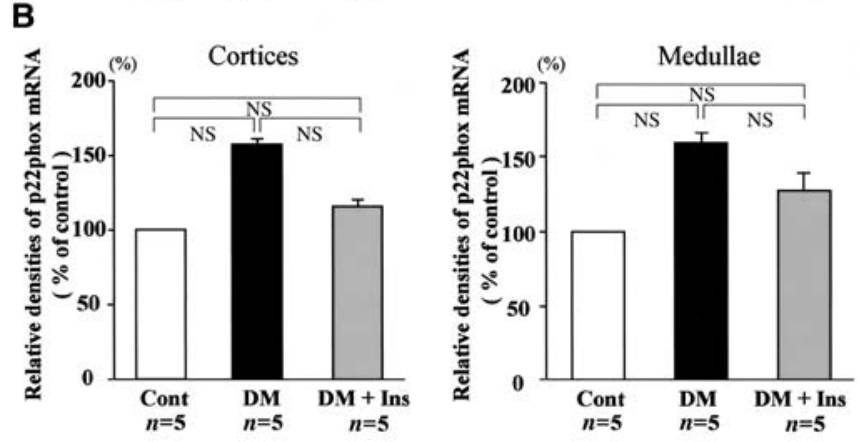

Fig. 6A, B. Effects of interventive insulin treatment on the increases in NOX4 (A) and p22phox mRNA expression (B) in the kidney from diabetic rats. Of streptozotocin-induced diabetic rats one-half were treated with insulin starting at 6 weeks after onset of diabetes. After the next 2 weeks of insulin treatment, NOX4 and p22phox mRNA expression levels were measured by Northern blot analysis. Levels of mRNA expression were normalized to $18 \mathrm{~S}$ rRNA and the results were expressed as mean percentages of control \pm SEM. Cont, control rats. DM, non-treated diabetic rats. $\mathrm{DM}+\mathrm{Ins}$, insulin-treated diabetic rats. $n$ number of rats. $* * p<0.01$

Control

p22phox
DM
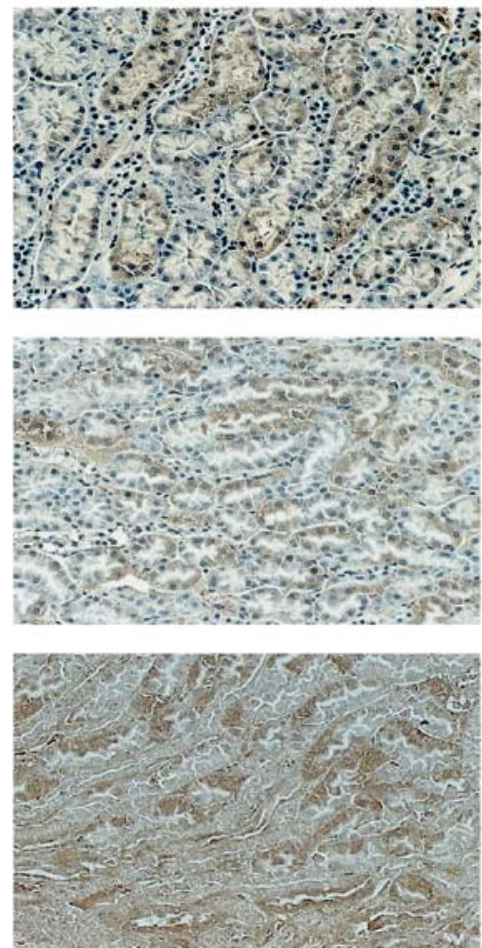

$\mathbf{D M}+\mathbf{I n s}$
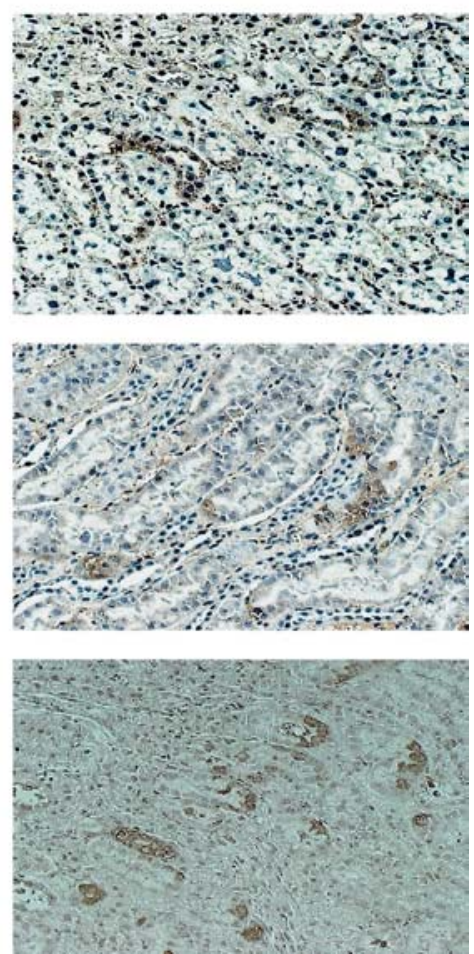

Fig. 7. Effects of interventive insulin treatment on NOX4, p22phox and 8-OHdG expression levels in renal tissue from diabetic rats. Of streptozotocin-induced diabetic rats one-half were treated by insulin starting at 6 weeks after onset of diabetes. After the next 2 weeks of insulin treatment, NOX4, p22phox and 8-OHdG expression levels were evaluated by immunostaining in renal tissue from control (Cont), non-treated diabetic (DM), and insulin-treated diabetic rats (DM+Ins). The pictures are representative of the samples from five control rats, five non-treated diabetic rats and five insulin-treated diabetic rats. Similar results were obtained in all samples from control, non-treated diabetic and insulin-treated diabetic rat kidneys 
A

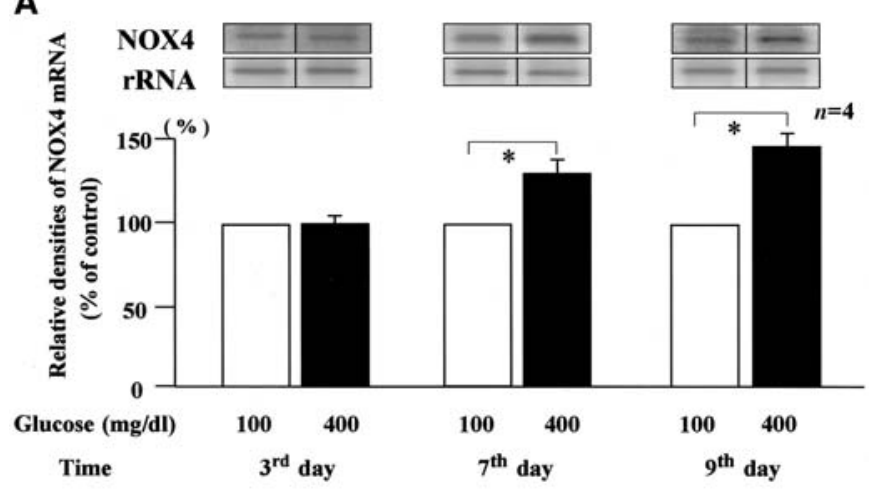

B

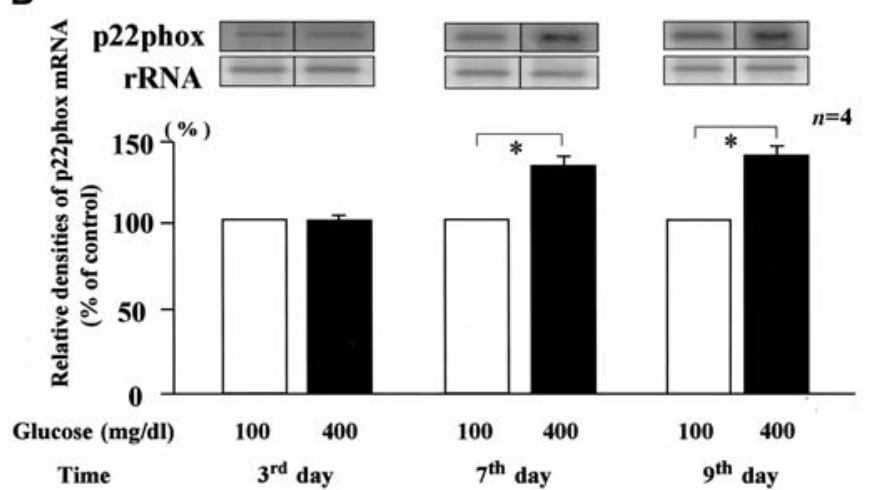

Fig. 8A, B. Effect of high glucose concentration on NOX4 (A) and p22phox (B) mRNA expression in cultured mesangial cells. Human mesangial cells were cultured in a Mesangial Cell Growth Medium (MsGM) supplemented with $0.5 \%$ serum and high glucose concentration $(400 \mathrm{mg} / \mathrm{dl})$ or normal glucose concentration $(100 \mathrm{mg} / \mathrm{dl})$. At the indicated time (3rd, 7th and 9th day), levels of NOX4 and p22phox mRNA expression were measured by Northern blot analysis. Levels of mRNA expression were normalized to $18 \mathrm{~S}$ rRNA and the results were expressed as mean percentages of control + SEM. $n$, number of independent experiments. ${ }^{*} p<0.01$

$211 \pm 8 \mathrm{mmol} / \mathrm{l}$ in insulin-treated diabetic rats, respectively. The results from insulin-treated diabetic rats were compared to those from non-treated diabetic rats and control rats. The increased mRNA levels of both NOX4 and p22phox in diabetic rats were completely restored to those in control rats by interventive insulin treatment (Fig. 6). In addition, immunostaining analysis showed that the increased expression levels of these components in tubular cells and glomeruli (data not shown) in diabetic rats were also restored to control levels in parallel with those of 8-OHdG (Fig. 7).

Effect of high glucose concentration on mRNA expression of NOX4 and p22phox in mesangial cells. Human mesangial cells were allowed to reach confluence in $100-\mathrm{mm}$ dishes, and then the medium was changed to a MsGM supplemented with $0.5 \%$ serum and high glucose level $(400 \mathrm{mg} / \mathrm{dl})$ or normal glucose level $(100 \mathrm{mg} / \mathrm{dl})$. Firstly, the effect of high glucose level
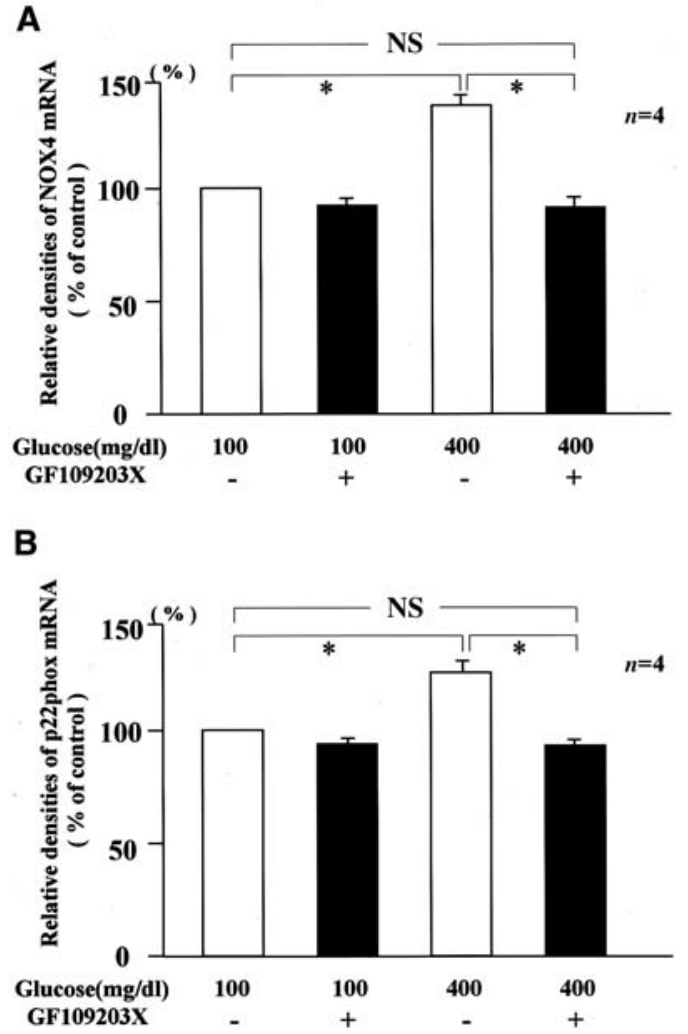

Fig. 9A, B. Effect of PKC inhibitor on high glucose-induced increases in NOX4 (A) and p22phox (B) mRNA expression in cultured mesangial cells. Human mesangial cells were cultured in a Mesangial Cell Growth Medium (MsGM) supplemented with $0.5 \%$ serum and high glucose concentration $(400 \mathrm{mg} / \mathrm{dl})$ or normal glucose concentration $(100 \mathrm{mg} / \mathrm{dl})$ for 9 days. In experiments with GF109203X, the cells were co-incubated with GF109203X $\left(5 \times 10^{-7} \mathrm{~mol}\right)$ for the last 2 days. Levels of NOX4 and p22phox mRNA expression were measured by Northern blot analysis. Levels of mRNA expression were normalized to 18S rRNA and the results were expressed as mean percentages of control + SEM. $n$, number of independent experiments. * $p<0.01$

on ROS production in cultured mesangial cells was examined using electron spin resonance (ESR) spectroscopy. Exposure to a high glucose concentration for 3 days induced a significant $(p<0.01)$ increase in ROS production as compared with exposure to a normal glucose concentration. At this time point, neither NOX4 nor p22phox mRNA level showed any difference between cells exposed to a high glucose concentration and a normal glucose concentration (Fig. 8). In addition, this high glucose concentration-induced increase in ROS production was completely restored by both treatment of $\mathrm{NAD}(\mathrm{P}) \mathrm{H}$ oxidase inhibitor diphenylene iodonium cloride $\left(10^{-5} \mathrm{~mol}\right)$ for $2 \mathrm{~h}$ and PKC inhibitor GF109203X $\left(5 \times 10^{-7} \mathrm{M}\right)$ for $2 \mathrm{~h}$ (data not shown). In contrast, at a longer time point (7th or 9th day), a high glucose concentration induced a significant increase in both the level of NOX4 and p22phox mRNA expression (7th day, $p<0.01, p<0.01$, respectively; 9th day, $p<0.01, p<0.01$, respectively) in paral- 
lel with an increase in ROS production. These increases were also completely reversed by the co-treatment with GF109203X for the last 2 days (Fig. 9). Similar results were obtained with the co-treatment of another PKC inhibitor, calphostin $\mathrm{C}\left(5 \times 10^{-7} \mathrm{~mol}\right)$.

\section{Discussion}

An increased production of reactive oxygen species (ROS) is thought to contribute to the development of diabetic vascular complications [1, 2, 3, 4, 5, 6]. Since the kidney is a susceptible organ to oxidative damage $[22,23]$, oxidative stress could play a role in the development of diabetic nephropathy as in other diabetic vascular complications. However, the source of ROS production is not fully understood. In blood vessels, attention was recently focused on $\mathrm{NAD}(\mathrm{P}) \mathrm{H}$ oxidase as the most important source of $\operatorname{ROS}[9,10,11,12]$. In addition, compelling evidence has accumulated to support a role for $\mathrm{NAD}(\mathrm{P}) \mathrm{H}$ oxidase in the pathophysiology of vascular diseases including hypercholesterolaemia [13], atherosclerosis [14, 15, 16], and hypertension [17]. In the kidney, NOX4 has recently been cloned as a homolog of gp91phox, the catalytic subunit of $\mathrm{NAD}(\mathrm{P}) \mathrm{H}$ oxidase $[25,26]$. NOX4 protein exhibited $39 \%$ identity to gp91phox with several conservation in membrane-spanning regions and binding sites for heme, FAD, and $\mathrm{NAD}(\mathrm{P}) \mathrm{H}$, indicative of its function as a superoxide-producing $\mathrm{NAD}(\mathrm{P}) \mathrm{H}$ oxidase. Indeed, overexpression of NOX4 in culture cells lead to increased superoxide production [26]. It is therefore implicated that NOX4, as a major source of ROS, could play a crucial role under pathological conditions. This study showed that mRNA levels of both NOX4 and p22phox were increased in the kidney of streptozotocin-induced diabetic rats at 4 and 8 weeks after onset of diabetes determined by Northern blot analysis. These increases at 8 weeks were completely normalized by interventive insulin treatment between 6 and 8 weeks after the onset of diabetes. This result clearly confirmed that these increases were caused by the diabetic state and not by a direct toxic effect of streptozotocin. Furthermore, by immunostaining analysis of NOX4 and p22phox, several important findings were obtained. Firstly, both NOX4 and p22phox were highly expressed in distal tubular cells and to a lesser extent expressed in glomeruli. Similar localization of NOX4 and p22phox is in agreement with the idea that gp91phox and p22phox stabilize each other [27]. Secondly, the expression levels of NOX4 and p22phox were apparently increased in both distal tubular cells and glomeruli from diabetic rats as compared with those from control rats, which was in agreement with the results of the Northern blot analysis. These data suggested that NOX4 and p22phox proteins were increased in the diabetic kidney at the transcription level. Lastly, immunostaining analysis of
8-OHdG, which is a marker of ROS-induced DNA damage, showed that the localization and levels of 8OHdG were quite in parallel with those of NOX4 and p22phox protein expression. The $8-\mathrm{OHdG}$ stains were apparently increased in both distal tubular cells and glomeruli from diabetic rats as compared with those from control rats. In addition, insulin treatment between 6 and 8 weeks after onset of diabetes completely restored the increased expression levels of NOX4 and p22phox to control levels in parallel with those of 8 -OHdG. These findings strongly support the idea that NOX4 and p22phox-produced superoxide and its derivative ROS could lead to renal tissue damage in diabetic rats. In contrast, as for intracellular localization of $8-\mathrm{OHdG}$, its stains were mainly increased in the cytosol and to a lesser extent increased in the nucleus in the renal tissues of diabetic rats. This finding suggests that ROS might damage mitochondrial DNA (mtDNA) predominantly, which is in agreement with our previous report showing that $8-\mathrm{OHdG}$ levels were increased in mtDNA rather than nuclear DNA in the diabetic kidney [6]. This seems to favour the role of mitochondria as a main source of ROS rather than NAD $(\mathrm{P}) \mathrm{H}$ oxidase because phagocytic NAD(P)H oxidase, by utilizing intracellular NADPH or NADH, transfers electrons across the membrane to extracellular oxygen to produce superoxide extracellularly. However, in vascular cells, it has been suggested that $\mathrm{NAD}(\mathrm{P}) \mathrm{H}$ oxidase-dependent superoxide and its derivative ROS could be produced not only extracellularly but also intracellularly $[10,18,28]$. In addition, it is also possible that long-lived ROS such as hydrogen peroxide are membrane permeable and would diffuse into the cells and inside mitochondria even if they are produced extracellularly. The predominant damage of mtDNA could be ascribed to the fact that mtDNA is vulnerable to oxidative damage due to the lack of histone and because the repair system of mtDNA is less active than that of nuclear DNA [29].

Several reports have shown that the activity of $\mathrm{NAD}(\mathrm{P}) \mathrm{H}$ oxidase, in parallel with the levels of its subunit protein (p22phox, p47phox or p67phox), are increased in the aorta from animal models of diabetes $[19,20]$ and in the saphenous vein and internal mammary artery of diabetic patients with coronary artery disease [21]. Taken together, these results suggest that $\mathrm{NAD}(\mathrm{P}) \mathrm{H}$ oxidase might play a crucial role in the development of diabetic vascular complications including nephropathy. However, the regulation mechanism of vascular NAD(P)H oxidase is still uncertain [25]. Previously, we showed that a high glucose concentration, a key manifestation of diabetes, could stimulate ROS production through protein kinase $\mathrm{C}$ (PKC)-dependent activation of $\mathrm{NAD}(\mathrm{P}) \mathrm{H}$ oxidase in cultured aortic endothelial cells and smooth muscle cells [18]. In this study, this finding was confirmed in cultured mesangial cells exposed to a high glucose concentration for 3 days. Our study also showed that at a longer 
time point (7th or 9th day), a high glucose concentration induced increases in both levels of NOX4 and p22phox mRNA expression, which were also completely reversed by the co-treatment with PKC inhibitor for the last 2 days. Taken together, the results suggest that high glucose concentration induced increased expression of $\mathrm{NAD}(\mathrm{P}) \mathrm{H}$ oxidase components as well as activation of this enzyme through a PKC-dependent mechanism. However, it should not be ruled out that increased expression of $\mathrm{NAD}(\mathrm{P}) \mathrm{H}$ oxidase components might be induced secondarily as a result of persistent activation of this enzyme. It is well established that the diabetic state as well as a high glucose concentration induce PKC activation in vascular tissues including renal tissues $[30,31,32]$ and the involvement of PKC in diabetes-induced renal dysfunction has been shown in animal models [33]. PKC activation might be associated with the increased expression of NOX4 and p22phox in the diabetic kidney.

In conclusion, this study provides evidence that $\mathrm{NAD}(\mathrm{P}) \mathrm{H}$ oxidase subunits, NOX4 and p22phox, were increased in the kidney of the diabetic rat. $\mathrm{NAD}(\mathrm{P}) \mathrm{H}$-dependent overproduction of ROS might contribute to the development of diabetic nephropathy. Thus, NAD $(\mathrm{P}) \mathrm{H}$ oxidase might be a new therapeutic target for preventing the development of diabetic nephropathy.

Acknowledgements. This work was supported by a Grant-inAid for Scientific Research (no. 11671126) from the Ministry of Education, Science and Culture, Japan, and was supported, in part, by the Takeda Medical Fund. This work was partly carried out at Kyushu University Station for Collaborative Research.

\section{References}

1. Baynes JW (1991) Role of oxidative stress in development of complications in diabetes. Diabetes 40:405-412

2. Williamson JR, Chang K, Frangos M et al. (1993) Hyperglycemic pseudohypoxia and diabetic complications. Diabetes 42:801-813

3. Brownlee M, Cerami A, Vlassara H (1988) Advanced glycosylation end products in tissue and the biochemical basis of diabetic complications. N Engl J Med 318:1315-1321

4. Spitaler MM, Graier WF (2002) Vascular targets of redox signaling in diabetes mellitus. Diabetologia 45:476-494

5. Ha H, Kim C, Son Y, Chung MH, Kim KH (1994) DNA damage in the kidneys of diabetic rats exhibiting microalbuminuria. Free Radic Biol Med 16:271-274

6. Kakimoto M, Inoguchi T, Sonta T et al. (2002) Accumulation of 8-hydroxy-2'-deoxyguanosine and mitochondrial DNA deletion in kidney of diabetic rats. Diabetes 51:15881595

7. Tesfamariam B, Brown ML, Cohen RA (1992) Aldose reductase and myo-inositol in endothelial cell dysfunction caused by elevated glucose. J Pharmacol Exp Ther 263: $153-157$

8. Nishikawa T, Edelstein D, Du XL et al. (2000) Normalizing mitochondrial superoxide production blocks three pathways of hyperglycaemic damage. Nature 404:787-790
9. Mohazzab KM, Kaminski PM, Wolin MS (1994) NADH oxidoreductase is a major source of superoxide anion in bovine coronary artery endothelium. Am J Physiol 266: H2568-H2572

10. Griedling KK, Minieri CA, Ollerenshaw JD, Alexander RW (1994) Angiotensin II stimulates NADH and NADPH oxidase activity in culured vascular smooth muscle cells. Circ Res 74:1141-1148

11. Rajagopalan S, Kurz S, Munzel T et al. (1996) Angiotensin II-mediated hypertension in the rat increases vascular superoxide production via membrane NADH/NADPH oxidase activation. J Clin Invest 97:1916-1923

12. Ushio-Fukai M, Zafari AM, Fukui T, Ishizuka N, Griendling KK (1996) p22phox is a critical component of the superoxide-generating NADH/NADPH oxidase system and regulates angiotensin II-induced hypertrophy in vascular smooth muscle cells. J Biol Chem 271:23317-23321

13. Warnholtz A, Nickenig G, Schulz E et al. (1999) Increased NADH-oxidase-mediated superoxide production in the early stages of atherosclerosis. Circulation 99:2027-2033

14. Azumi H, Inoue N, Takeshita S et al. (1999) Expression of NADH/NADPH oxidase p22phox in human coronay arteries. Circulation 100:1494-1498

15. Barry-Lane PA, Patterson C, Merwe $M$ van der et al. (2001) p47phox is required for atherosclerotic lesion progression in Apo E -/- mice. J Clin Invest 108:1513-1522

16. Sorescu D, Weiss D, Lassegue B et al. (2002) Superoxide production and expression of Nox family proteins in human atherosclerosis. Circulation 105:1429-1435

17. Fukui T, Ishizaka N, Rajagopalan S et al. (1997) p22phox mRNA expression and NADPH oxidase activity are increased in aortas from hypertensive rats. Circ Res 80:45-51

18. Inoguchi T, Li P, Umeda F et al. (2000) High glucose level and fatty acid atimulate reactive oxygen spieces production through protein kinase $\mathrm{C}$-dependent activation of $\mathrm{NAD}(\mathrm{P}) \mathrm{H}$ oxidase in cultured vascular cells. Diabetes 49:1939-1945

19. Hink U, Li H, Mollnau H et al. (2001) Mechanisms underlying endothelial dysfunction in diabetes mellitus. Circ Res 88:e14-e22

20. Kim YK, Lee MS, Son SM et al. (2002) Vascular NADH oxidase is involved in impaired endothelium-dependent vasodilation in OLETF rats, a model of type 2 diabetes. Diabetes 51:522-527

21. Guzik TJ, Mussa S, Gastaldi D et al. (2002) Mechanisms of increased vascular superoxide production in human diabetes mellitus. Circulation 105:1656-1662

22. Laurent B, Ardaillou R (1986) Reactive oxygen species: production and role in the kidney. Am J Physiol 251:F765F776

23. Ueda N, Kaushal GP, Shah SV (2000) Apoptotic mechanisms in acute renal failure. Am J Med 108:403-415

24. Griendling KK, Sorescu D, Ushio-Fukai M (2000) $\mathrm{NAD}(\mathrm{P}) \mathrm{H}$ oxidase-role in cardiovascular biology and disease. Circ Res 86:494-501

25. Geiszt M, Kopp JB, Varnai P, Leto TL (2000) Identification of Renox, an NAD(P)H oxidase in kidney. Proc Natl Acad Aci USA 97:8010-8014

26. Shiose A, Kuroda J, Tsuruya K et al. (2001) A novel superoxide-producing NAD(P)H oxidase in kidney. J Biol Chem 276:1417-1423

27. Parkos CA, Allen RA, Cochrane CG, Jesaitis AJ (1987) Purified cytochrome $b$ from human granulocyte plasma membrane is comprised of two polypeptides with relative molecular weights of 91,000 and 22,000. J Clin Invest 80:732-742

28. Suh YA, Arnold RS, Lassegue B et al. (1999) Cell transformation by the superoxide-generating oxidase Mox1. Nature 401:79-82 
29. Merriwether DA, Clark AG, Ballinger SW et al. (1991) The structure of human mitochondrial DNA variation. J Mol Evol 33:543-555

30. Ishii H, Jirousek MR, Koya D et al. (1996) Amelioration of vascular dysfunctions in diabetic rats by an oral PKC $\beta$ inhibitor. Science 272:728-731

31. Inoguchi T, Battan R, Handler E, Sportsman JR, Heath W, King GL (1992) Preferential elevation of protein kinase C isoform $\beta I I$ and diacylglycerol levels in the aorta and heart of diabetic rats: differential reversibility to glycemic control by islet cell transplantation. Proc Natl Acad Sci USA 89:11059-11063

32. Shiba T, Inoguchi T, Sportsman JR, Heath WF, Bursell S, King GL (1993) Correlation of diacylglycerol level and protein kinase $\mathrm{C}$ activity in rat retina to retinal circulation. Am J Physiol 265:E783-E793
33. Koya D, King GL (1998) Protein kinase C activation and the development of diabetic complications. Diabetes 47: 859-866

34. Swain SD, Helgerson SL, Davis AR, Nelson LK, Quinn MT (1997) Analysis of activation-induced conformational changes in $\mathrm{p} 47$ phox using tryptophan flurescence spectroscopy. J Biol Chem 272:29502-29510

35. Benna JE, Dang PMC, Gaudry M et al. (1997) Phosphorylation of the respiratory burst oxidase sbunit p67phox during human neutrophil activation: regulation by protein kinase C-dependent and independent pathways. J Biol Chem 272:17204-17208

36. Akasaki T, Koga H, Sumimoto H (1999) Phosphoinositide 3-kinase-dependent and -independent activation of the small GTPase Rac2 in human neutrophils. J Biol Chem 274:18055-18059 